\title{
Morphological, Mechanical and Physio-chemical Performance of ortho-Cresol Epoxy Novolac Based Vinyl Ester Resin
}

\author{
Shipra Jaswal, Bharti Gaur* \\ National Institute of Technology, Department of Chemistry, Hamirpur, H.P., India \\ "Corresponding author: e-mail: bhartigaur@gmail.com
}

\begin{abstract}
Vinyl ester resin (VEOCN) was prepared from o-cresol epoxy resin (EOCN) and methacrylic acid in the presence of triphenyl phosphine as catalyst and hydroquinone as inhibitor with acid value of $\sim 7 \mathrm{mg}$ of $\mathrm{KOH}$ per gram of solid. O-cresol based novolac resin (OCN), OCN based epoxy resin (EOCN) and VEOCN were characterized by Fourier transform infra red spectroscopy (FT-IR), ${ }^{1} \mathrm{H}-\mathrm{NMR}$ and ${ }^{13} \mathrm{C}-\mathrm{NMR}$. The thermal and mechanical behavior of the samples prepared at $30^{\circ} \mathrm{C}$ from VEOCN using styrene and methyl-methacrylate respectively as reactive diluents, in the presence of benzoyl peroxide (2 phr) as initiator was studied using Differential Scanning Calorimetry (DSC), Thermogravimetric analysis (TGA) and Universal Testing Machine (UTM). Chemical resistance of above VER samples was also evaluated as a function of \% weight loss and with the help of Scanning Electron Microscopy (SEM), upon immersing the VEOCN samples in different solutions for 90 days.
\end{abstract}

Keywords: thermosetting resins, crosslinking reactions, thermal behavior, mechanical properties, chemical resistance.

\section{INTRODUCTION}

There has been escalating attention into the study of vinyl ester (VE) resins - an efficient category of thermosetting resins in polymer industry. VE resins were first introduced commercially in early 1960s. Vinyl ester (VE) resins encompass exceptional mechanical and chemical properties coupled with outstanding corrosion resistance and heat performance, which makes them a good selection for many end uses, such as polymer matrix composites and especially fibre reinforced polymer (FRP) for construction applications ${ }^{1-3}$, coatings for solvent storage tanks, sewer pipes ${ }^{4-6}$ and adhesives ${ }^{7}$ etc. VE resins are the reaction product of equal amount of polyepoxide and $\alpha-\beta$ unsaturated carboxylic acids ${ }^{8-10}$. The reactive unsaturation of these resins, present as terminal groups can be crosslinked with or without reactive monomers or diluents having vinylic groups e.g. styrene, different acrylates and vinyl toluene etc. These reactive monomers or diluents are used to reduce the resin viscosity and to improve overall polymer performance such as crosslink density, mechanical strength, percent elongation, hardness, chemical resistance, scratch resistance and surface finish etc. by delaying the gelation process of neat VE resins ${ }^{11-17}$. Although VE resins have extensively been used in industry for many years, they are still categorized together with the unsaturated polyester (UPE) resins because of the structural resemblance with UPE resins. The last few decades have witnessed an ever increasing need to synthesize new vinyl ester resins having new structural properties and better performance. A need is also always felt to explore the structure property relationship owing to the participation of different reactive monomers as diluents in the crosslinking reactions.

In the current communiqué, vinyl ester resin using o-cresol has been synthesized and their thermal, mechanical, chemical and morphological behaviors have been investigated in the presence of styrene and methyl-methacrylate as reactive monomers.

\section{EXPERIMENTAL}

o-cresol $(\mathrm{CDH})$, formaldehyde [37-41\% solution, Fisher scientific] and Epichlorohydrin L.R. grade (Lobachemie), Sodium hydroxide pellets (Merck) were used for preparation of novolacs and epoxy novolacs, respectively. Methacrylic acid (Lobachemie) and triphenyl phosphine (Lobachemie) were used for synthesis of vinyl ester resins according to the known method, cited in previous research article ${ }^{18}$. Styrene (ACROS ORGANICS) and methyl methacrylate $(\mathrm{CDH})$ were used as reactive monomers or diluents in the present study.

Synthesis of o-cresol based novolac resin (OCN) and epoxy resin based on o-cresol novolac resin (EOCN) was done according to the method reported in our previous research article ${ }^{18}$.

\section{Synthesis of vinyl ester resin from ortho-cresol epoxy novolac (VEOCN)}

Vinyl ester resin was prepared using 1:0.9 molar ratios of o-cresol epoxy novolac resin (epoxide equivalent weight $=164 \mathrm{~g} /$ eq. by pyridinium chloride method $^{19}$ ) and methacrylic acid in the presence of triphenyl phosphine (1 phr by weight of epoxy resin) and hydroquinone (200 ppm) at $85 \pm 1^{\circ} \mathrm{C}$ for three and a half hours to obtain a product with acid value of $\sim 7 \mathrm{mg}$ of $\mathrm{KOH} / \mathrm{gm}$ solids determined according to ASTM D 1636.

\section{CHARACTERIZATION}

\section{Structural characterization}

The structural characterization of o-cresol formaldehyde novolac (OCN) was done using FT-IR, ${ }^{1} \mathrm{H}-\mathrm{NMR}$ and ${ }^{13} \mathrm{C}$-NMR spectroscopy. Also, the characterization of o-cresol epoxy novolac resin (EOCN) and vinyl ester resins based on o-cresol epoxy novolac resin (VEOCN) was done using FTIR and ${ }^{1} \mathrm{H}-\mathrm{NMR}$ spectroscopy. The FTIR spectra of the samples were recorded by dissolving in chloroform and subsequent evaporation of solvent on $\mathrm{KBr}$ disc. Perkin Elmer FTIR Spectrometer was used for this purpose. The ${ }^{1} \mathrm{H}$-NMR and ${ }^{13} \mathrm{C}$-NMR spectra 
of these samples were recorded using Bruker Avance II $400 \mathrm{NMR}$ spectrometer, $\mathrm{CDCl}_{3}$ as solvent and tetramethylsilane as an internal standard.

\section{Determination of physical properties}

The refractive indices (RIs) of the VEOCN samples containing styrene and MMA were measured by means of an Abbe's refractometer. Viscosities of the VEOCN samples containing $40 \% \mathrm{w} / \mathrm{w}$ styrene and MMA were also measured by using Brookfield viscometer (LVDV II + Pro, Brookfield, USA) using spindle no. L62 at 120 $\mathrm{rpm}$. Density measurements for the above samples were also performed at $25^{\circ} \mathrm{C}$ using pycnometer.

\section{Gel Permeation Chromatography (GPC)}

Molecular weight of o-cresol epoxy novolac based vinyl ester resin (VEOCN) was recorded with Turbo matrix - 40 (Perkin Elmer) Gel Permeation Chromatograph. The column used for GPC calibration was of crosslinked polystyrene. Tetrahydrofuran (THF) was used both as mobile and stationary phase for the experiment.

Curing and Decomposition behaviour of ortho-cresol epoxy novolac based vinyl ester resin

The samples for curing and decomposition behaviour were prepared by mixing 10/4/0.2 (w/w) of o-cresol epoxy novolac based vinyl ester resin, reactive monomers-styrene, methyl methacrylate and free radical initiatorbenzoyl peroxide, respectively, in small glass vial and stirred vigorously with a glass rod at $30^{\circ} \mathrm{C}$ until the mixtures became homogeneous in nature. A Diamond DSC (Perkin Elmer) was used to record the DSC scans of the above samples by taking $\approx 2 \mathrm{mg}$ of the sample into shallow aluminium pan sealed by an aluminium cover under dynamic conditions with program rate of $10^{\circ} \mathrm{C} \mathrm{min}-1$ from $35^{\circ} \mathrm{C}$ to the temperature at which the exothermic reactions were completed.

From the dynamic DSC scans, a temperature was selected at which an appreciable rate of curing could be observed. DSC runs under isothermal conditions at the selected temperatures were then carried out to determine the apparent time required for the completion of each of the curing reactions. The curing conditions (temperature and time) thus determined were used to cure the resin samples for subsequent studies on thermal stability. An EXSTAR TG/DTG 6300 was used to record TG/DTG traces in nitrogen atmosphere (flow rate $=200$ $\mathrm{mLmin}^{-1}$ ) at heating rate of $10^{\circ} \mathrm{C} \mathrm{min}^{-1}$ with sample size $11 \pm 5 \mathrm{mg}$. The relative thermal stability of the resin was quantitatively estimated by comparing the temperatures for a particular degree of weight loss.

\section{Mechanical Behavior}

In mechanical characterization, the mechanical properties such as compressive strength (as per ASTM D3410), flexural strength (as per ASTM D790), elongation at break (in \%) and tensile strength (as per ASTM D3039) of o-cresol epoxy novolac based vinyl ester resin, cured using styrene and methyl methacrylate as reactive monomers were determined by Hounsefield-25KN universal testing machines at deformation rate of $2 \mathrm{~mm} / \mathrm{min}$.

Impact tests were also carried out on VEOCN samples containing styrene and MMA as per ASTM D256 using a plastic impact tester (Tinius Olsen). The pendulum type impact testing machine ascertains the notch impact strength of the material by shattering the notched specimen with a pendulum hammer, measuring the spent energy and relating to the cross section of the specimen. The standard specimen for ASTM D256 is $50 \times 10 \times 2$ $\mathrm{mm}$ and depth under the notch is $2 \mathrm{~mm}$. The machine is adjusted such that the blade on the free hanging pendulum just barely contacts the specimen (zero position). The density of the cured vinyl ester resin is calculated by using Archimedian principle of weighing small pieces cut from the large samples first in air and then in water.

\section{Chemical Resistance}

Chemical resistance behavior in terms of percent weight loss of the cured resin samples was studied by plunging the samples of identified weights in $1 \mathrm{M} \mathrm{HCl}$, $1 \mathrm{M} \mathrm{NaOH}$ and $1 \mathrm{M} \mathrm{NaCl}$ solutions for 90 days at room temperature. Percent weight loss was then calculated using the following formula:

$$
\% \text { Weight loss }=\frac{\mathrm{W}_{\mathrm{i}}-\mathrm{W}_{\mathrm{f}}}{\mathrm{W}_{\mathrm{i}}} \times 100
$$

where, $\mathrm{W}_{\mathrm{i}}=$ Dry weight of the sample before immersion $\mathrm{W}_{\mathrm{f}}=$ Dry weight of the sample after immersion

\section{Scanning Electron Microscopy (SEM)}

SEM was also used to analyze morphological change on the surface of cured vinyl ester resin samples (containing MMA and styrene as reactive monomers) due to chemical exposure given to study the chemical resistance of the samples. The SEM analysis was performed by JSM- 6610 machine and to enhance the conductivity of the samples thin film of gold was mounted on the samples before the SEM photographs were taken.

\section{RESULTS AND DISCUSSION}

VER sample (VEOCN) was prepared using o -cresol epoxy novolac resin with acid value $\sim 7 \mathrm{mg} \mathrm{KOH} / \mathrm{g}$ solid and used for further studying thermal, mechanical, chemical and morphological behavior using styrene (Sty) and methyl methacrylate (MMA) as reactive monomers. The number average molecular weight $\left(\mathrm{M}_{\mathrm{n}}\right)$ of o -cresol epoxy novolac based vinyl ester resin (VEOCN) was determined by using Gel Permeation Chromatograph (GPC) and which was found to be $245 \mathrm{~g} / \mathrm{mol}$. Figure 1 shows scheme for the reaction of epoxy novolac with methacrylic acid catalyzed with triphenylphosphene and Figure 2 depicts the curing of vinyl ester resin in presence of MMA as reactive monomer and benzoyl peroxide (BP) as free radical initiator. The physio-chemical properties of the VEOCN resin samples are summarized in Table 1.

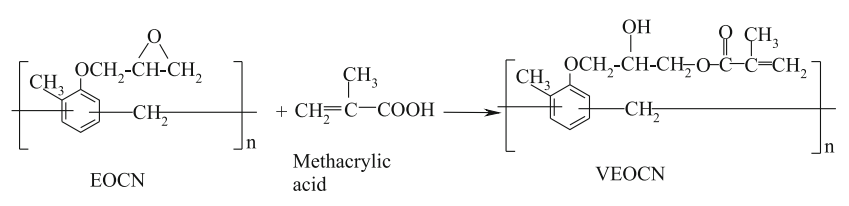

Figure 1. Scheme for reaction of epoxy novolac with methacrylic acid catalysed with triphenylphosphine 
Table 1. The physico-chemical properties of VEOCN resin

\begin{tabular}{|l|c|c|c|}
\hline S.No. & Properties & VEOCN + MMA & VEOCN + Sty \\
\hline 1. & Density $\left[\right.$ in $\mathrm{g} / \mathrm{cm}^{3}$ at $\left.25^{\circ} \mathrm{C}\right]$ & 1.0314 & 0.9956 \\
\hline 2. & Viscosity $\left[\right.$ in $\left.\mathrm{cps}^{\circ} 25^{\circ} \mathrm{C}\right]$ & 2906 & 3114 \\
\hline 3. & Refractive Index & 1.478 & 1.414 \\
\hline
\end{tabular}<smiles>CC(=O)OCC(O)COc1cccc(C)c1CCC(C)C</smiles>

VER based on o-cresol epoxy novolac resin<smiles>CCOc1c(CC(O)COC(=O)CC(C)(CCC(C)(C)C(=O)OC)C(=O)OC)cccc1C(C)(C)C</smiles>

Figure 2. Scheme for curing of Vinyl ester resin with MMA as reactive diluent and benzoyl peroxide (BP) as free radical initiator

FT-IR, ${ }^{1} \mathrm{H}-\mathrm{NMR}$ and ${ }^{13} \mathrm{C}$-NMR spectroscopic analysis of OCN (o-cresol based novolac resin)

FT-IR, ${ }^{1} \mathrm{H}-\mathrm{NMR}$ and ${ }^{13} \mathrm{C}-\mathrm{NMR}$ spectroscopic analysis of OCN reveals the condensation of o-cresol with formaldehyde. FT-IR spectra of OCN resin in Figure 3 (a), shows the appearance of absorption peak at $3399 \mathrm{~cm}^{-1}$ due to intermolecular hydrogen bonded $-\mathrm{OH}$ stretching. Aromatic C-H stretching is observed at $3012 \mathrm{~cm}^{-1}$. The aliphatic methyl and methylene $\mathrm{C}-\mathrm{H}$ stretching is also observed in the region of $2920-2850 \mathrm{~cm}^{-1}$. From the ${ }^{1} \mathrm{H}-\mathrm{NMR}$ spectra in Figure 4 (a), characteristic proton resonance signal due to - $\mathrm{OH}$ group of o-cresol is observed at $4.9 \mathrm{ppm}$. Resonance signals at $2.25 \mathrm{ppm}$ are due to $-\mathrm{CH}_{3}$ protons and the region between 3.7-4.0 ppm show the peaks due to methylene protons of the

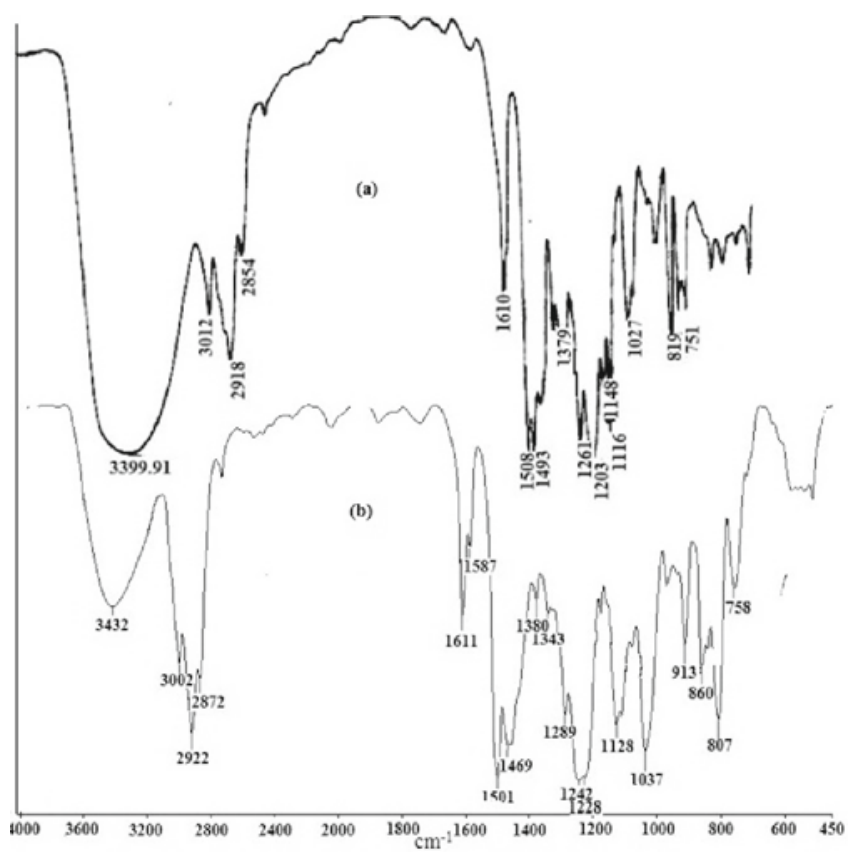

Figure 3. FT-IR spectra of (a) OCN, (b) EOCN
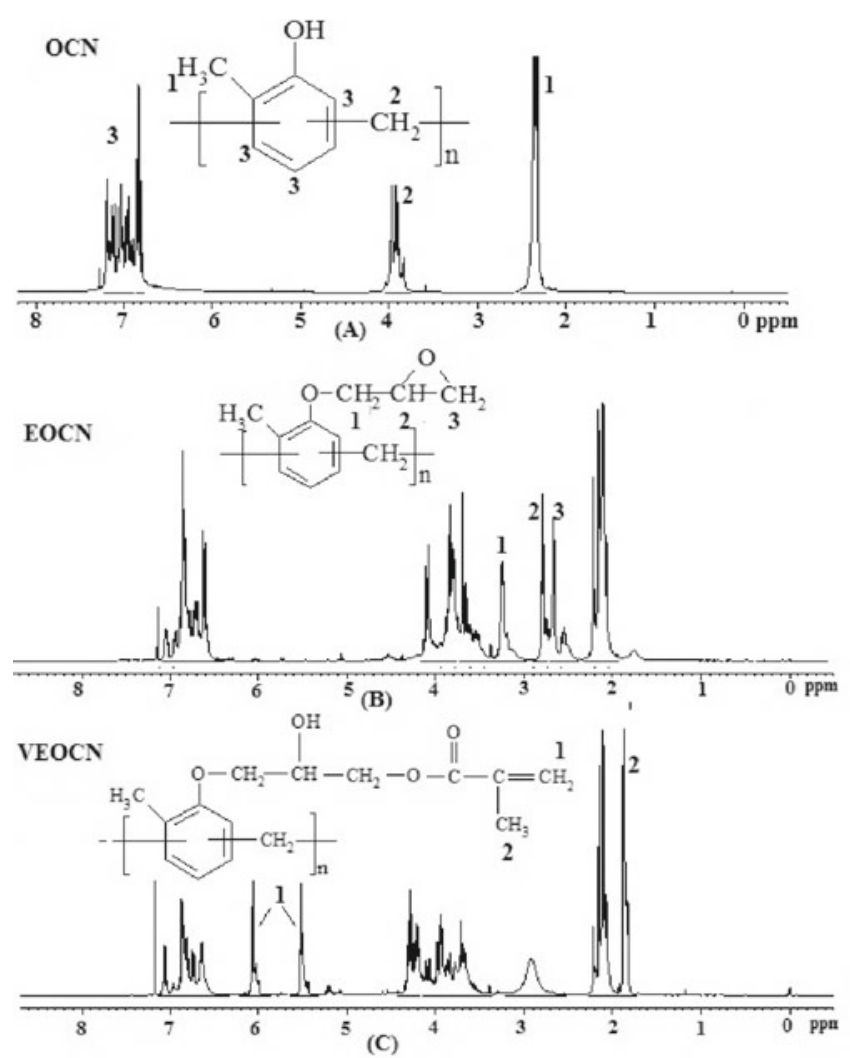

Figure 4. ${ }^{1} \mathrm{H}-\mathrm{NMR}$ spectra of (A) OCN, (B) EOCN and (C) VEOCN

polymer backbone. Aromatic protons are also observed at $6.7-7.3 \mathrm{ppm}$.

${ }^{13} \mathrm{C}$-NMR specifically confirms the ortho-ortho, ortho-para and para-para linkages in the $\mathrm{OCN}$ resin. Using ${ }^{13} \mathrm{C}-\mathrm{NMR}$, it has been reported that para-para methylene linkages formed most rapidly followed by ortho-para and ortho-ortho methylene linkages ${ }^{20}$. Figure 5, shows the ${ }^{13} \mathrm{C}$-NMR spectrum of OCN resin in which appearance of peaks at 31.4, 36.14 and 40.44 ppm confirms the ortho-ortho, ortho-para and para-para linkages between the phenyl rings, respectively, which further confirms that the OCN resin formed is a random novolac re$\sin ^{21}$. Appearance of peak at $152-155 \mathrm{ppm}$ is due to the hydroxyl bearing carbon. Peaks at 115.8-134.5 ppm

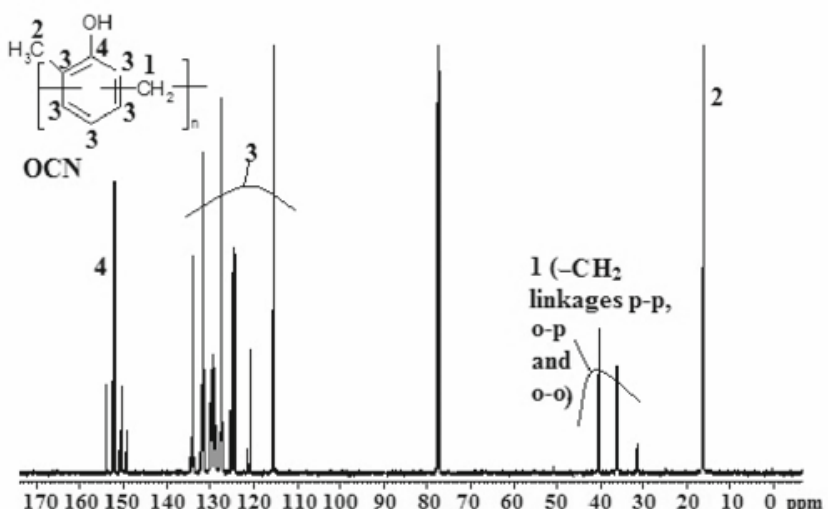

Figure 5. ${ }^{13} \mathrm{C}-\mathrm{NMR}$ of $\mathrm{OCN}$ 
represent the aromatic carbon atoms while the peak at $16.4 \mathrm{ppm}$ shows the presence of $-\mathrm{CH}_{3}$ groups on the aromatic rings.

\section{FT-IR and ${ }^{1} \mathrm{H}-\mathrm{NMR}$ spectroscopic analysis of EOCN and VEOCN}

FT-IR spectroscopic studies of EOCN, in Figure $3(\mathrm{~b})$, proves the epoxidation of $\mathrm{OCN}$ by appearance of characteristic band due to symmetrical stretching or ring breathing frequency of epoxy ring at $1242 \mathrm{~cm}^{-1}$ and asymmetrical C-O-C stretching in aryl alkyl ethers at 1228 $\mathrm{cm}^{-1}$. Also the peak at $3002 \mathrm{~cm}^{-1}$ shows the $\mathrm{C}-\mathrm{H}$ stretching of epoxy ring. On the other hand, FT-IR spectrum of VEOCN in Figure 6, shows the appearance of distinguished broad absorption band due to secondary hydroxyl group at $3433 \mathrm{~cm}^{-1}$, peaks at 1715 and $1170 \mathrm{~cm}^{-1}$ due to carbonyl groups of methacrylate and peak at $1631 \mathrm{~cm}^{-1}$ due to $\mathrm{C}=\mathrm{C}$ stretching of methacrylate groups verifies the formation of $\mathrm{VEOCN}$.

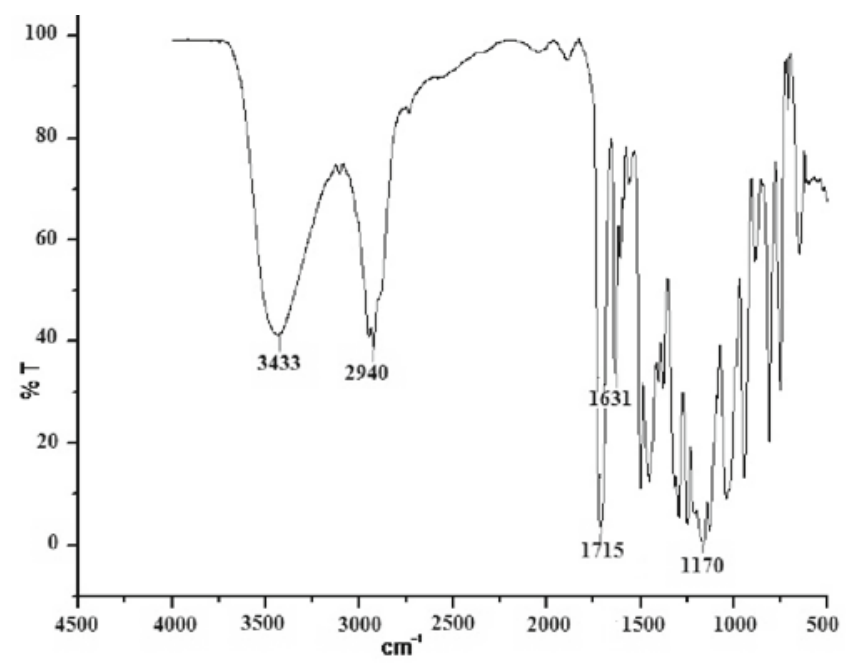

Figure 6. FT-IR of VEOCN

${ }^{1} \mathrm{H}-\mathrm{NMR}$ spectrum of EOCN in Figure 4 (b), shows characteristic proton resonance signals at 2.6, 3.2 and 3.6-3.8 ppm due to $-\mathrm{CH}_{2},-\mathrm{CH}$ and $-\mathrm{O}-\mathrm{CH}_{2}-$ protons of epoxy ring, respectively. Resonance signals at 2.16 ppm due to $-\mathrm{CH}_{3}$ can also be observed. Moreover, the proton resonance signal due to $-\mathrm{OH}$ group of o-cresol which is present in OCN resin are also absent in EOCN.

In proton NMR spectrum of VEOCN shown in Figure 4 (c), distinguished peaks at 5.5 and $6.1 \mathrm{ppm}$ are observed due to vinylic protons of methacrylate group. A broad proton resonance signal due to secondary $-\mathrm{OH}$ group is also been observed at $2.7-3.0 \mathrm{ppm}$.

\section{Curing behavior}

The curing behaviour of vinyl ester resin varies with the different reactive diluents. Typical DSC scans for the curing of o-cresol epoxy novolac based vinyl ester resin (VEOCN) with styrene and methyl methacrylate $(40 \%$ $\left.\mathrm{w} / \mathrm{w}^{22}\right)$, respectively, at a program rate of $10^{\circ} \mathrm{C} \mathrm{min}^{-1}$ have been given in Figure 7. It can be observed from the Figure 7 that the exothermic transitions for the curing of VEOCN with both the monomers are in the range of $85-150^{\circ} \mathrm{C}$. The onset temperatures $\left(\mathrm{T}_{\mathrm{i}}\right)$ are $105.2^{\circ} \mathrm{C}$ and $93.3^{\circ} \mathrm{C}$ and peak temperature $\left(\mathrm{T}_{\mathrm{p}}\right)$ are $118.1^{\circ} \mathrm{C}$ and $100.3^{\circ} \mathrm{C}$ for $\mathrm{VEOCN}$ samples containing styrene and methyl methacrylate, respectively. It can be observed that a)

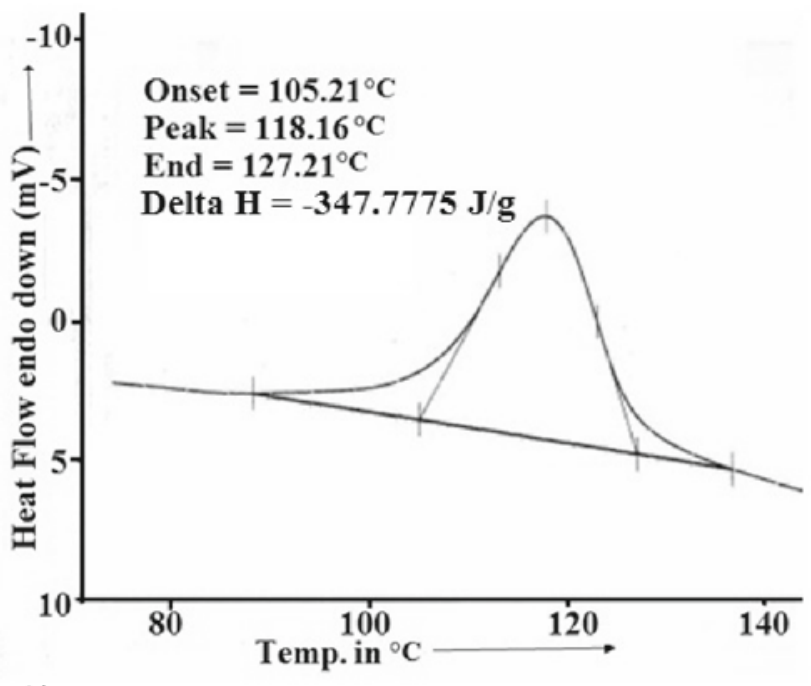

b)

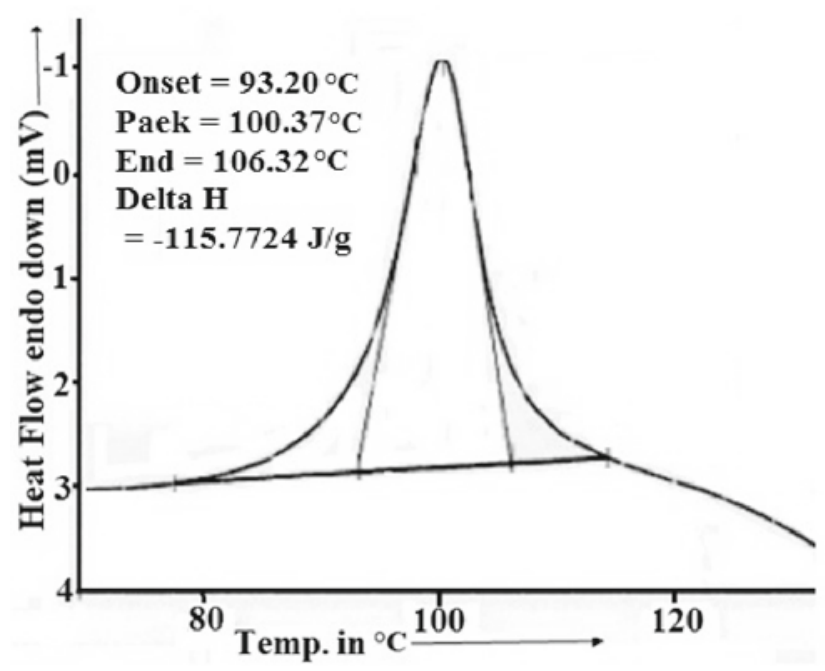

Figure 7. Dynamic DSC scans for curing at $10^{\circ} \mathrm{C} / \mathrm{min}$ of vinyl ester resin samples (A) VEOCN+Sty, (B) VEOCN+MMA

the onset and peak temperatures for VEOCN samples containing methyl methacrylate are lower than that of sample containing styrene which signifies that methyl methacrylate (MMA) is more reactive to $\mathrm{VEOCN}$ than styrene during curing in the presence of benzoyl peroxide (BP) as free radical initiator. Moreover, the enthalpy of the reaction $(\Delta \mathrm{H})$ is also observed to be lower for the VEOCN sample containing MMA than the sample containing styrene which signifies the higher degree of curing or crosslinking in VEOCN sample containing MMA than the samples containing styrene $\mathrm{e}^{\mathbf{2 3}}$. The explanation for this may be attributed to steric factor and greater resonance stability of styrene free radical. Furthermore, methyl methacrylate radical is more polar as compared to styrene and consequently more reactive.

\section{Thermogravimetric studies}

A comparative thermogravimetric (TGA) scan for isothermally cured samples of VEOCN with styrene and methyl methacrylate has been shown in Figure 8. The rate of decomposition at a specific temperature can be determined as the tangential slope of a TGA trace. In general, the temperature at maximum rate of decomposition, $\mathrm{T}_{\max }$ is of primary importance. The $\mathrm{T}_{\max }$ are $416^{\circ} \mathrm{C}$ and $415^{\circ} \mathrm{C}$ for cured VEOCN samples containing 


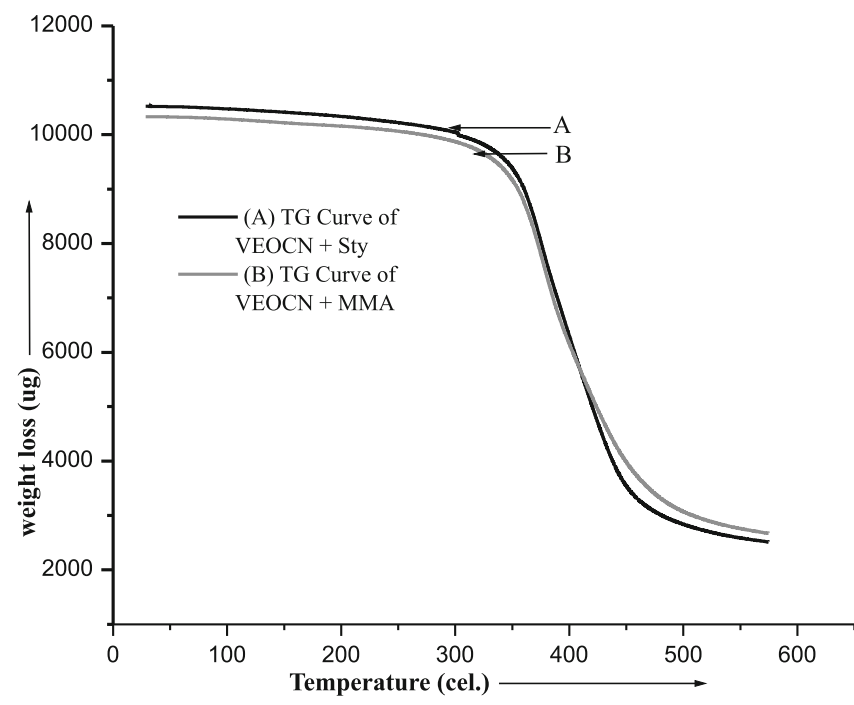

Figure 8. A comparative TGA scans for cured vinyl ester resin samples (A) VEOCN+STY, (B) VEOCN+MMA

styrene and methyl methacrylate, respectively. Also on comparing the weight loss in cured VEOCN sample containing styrene and methyl methacrylate from the Figure 8 , it is noticeable that the thermal stability of sample cured with styrene is higher than sample cured with methyl methacrylate (MMA) due to the presence of aromatic ring of styrene which provides rigidity to cured network of VEOCN.

\section{Mechanical characterization of VEOCN samples}

Density of the samples of VEOCN containing MMA and styrene is found to be 1.201 and $1.157 \mathrm{~g} / \mathrm{cm}^{3}$ respectively, using Archimedian principle. From the Table 2, it is examined that sample prepared from methyl methacylate as reactive monomer and VEOCN shows enhanced compression and flexural strength as compare to that of VEOCN sample containing styrene as reactive monomer, because of the higher degree of curing, which may be due to higher reactivity of MMA than styrene with VEOCN. However, the values of tensile strength, elongation at break and impact strength of VEOCN sample containing styrene as reactive monomer is found to be higher than that of VEOCN sample containing MMA. This may be due to the formation of more pronounced biphasic structure during curing, where the formation of polystyrene imparts more flexibility to the sample containing styrene $e^{22}$. During curing process, the physical state of thermoset resins changes from liquid to gel and ultimately to a glassy solid. It is believed that the heterogeneity of free-radical crosslinking systems during such reaction is an inherent result of the physical aspects of the free-radical reaction and is explained through widely accepted micro-gel theory ${ }^{24-30}$. The curing of VEOCN/styrene or VEOCN/MMA, like vinyl-divinyl system ${ }^{31}$, shows an induction period due to the presence of inhibitors and cage effect ${ }^{32}$ in which the inhibitor consumes the free radicals and very little polymerization takes place. In the first stage which is the period of accelerated propagation, the reactive monomer reacts at a slower rate than the VEOCN monomer. The kinetics of copolymerization is thought to be governed by the intrinsic reactivity of the styrene or MMA and VEOCN double bonds and not by diffusion. After this stage, polymerization of VEOCN monomer decreases and polymerization of vinylic monomer increases. The reason for this is attributed to the higher mobility of the vinylic molecule in the entire network, owing to its smaller size. The VEOCN double bond becomes immobile in the network due to its larger size. Towards the end of the reaction the VEOCN ceases to react while the rate of consumption of vinylic monomer continues to increase, which leads to the formation of polystyrene or polymethyl methacrylate until the vitrification takes place $^{33-34}$. The homopolymerized chains formed cannot be extracted from the fully cured sample as these chains are either entangled within the matrix or that each chain is independently grafted to the matrix ${ }^{35}$. The MMA monomer since has higher reactivity as compared to styrene monomer is able to copolymerize more with VEOCN rather than getting homopolymerized.

\section{Chemical Resistance VEOCN samples}

Chemical resistance studies are performed as a function of $\%$ weight loss upon immersing the VEOCN samples in $1 \mathrm{M} \mathrm{HCl}, 1 \mathrm{M} \mathrm{NaOH}$ and $1 \mathrm{M} \mathrm{NaCl}$ solutions for 90 days. The chemical resistance results of resin samples containing MMA and Styrene have been reported in Table 3. From the Table 3, it is evident that cured VEOCN sample containing MMA shows high acid, base

Table 2. The mechanical properties of the VEOCN samples containing styrene and MMA as reactive diluents

\begin{tabular}{|l|c|c|c|c|c|c|}
\hline S.No. & Sample & $\begin{array}{c}\text { Compression } \\
\text { Strength [MPa] }\end{array}$ & $\begin{array}{c}\text { Flexural Strength } \\
{[\mathrm{MPa}]}\end{array}$ & $\begin{array}{c}\text { Tensile } \\
\text { Strength [MPa] }\end{array}$ & $\begin{array}{c}\text { Impact } \\
\text { Strength [J] }\end{array}$ & Elongation [\%] \\
\hline 1. & $\begin{array}{c}\text { VEOCN+M } \\
\text { MA }\end{array}$ & 83.6 & 63.8 & 30.0 & 0.9867 & 5.12 \\
\hline 2. & VEOCN+Sty & 40.0 & 5.0 & 39.1 & 1.094 & 9.20 \\
\hline
\end{tabular}

Table 3. Chemical resistance of VEOCN samples containing MMA and Styrene

\begin{tabular}{|c|c|c|c|}
\hline \multirow[b]{2}{*}{$\begin{array}{l}\text { Solvent } \\
\text { used }\end{array}$} & \multirow[b]{2}{*}{ No. of Days } & \multicolumn{2}{|c|}{ Samples } \\
\hline & & $\begin{array}{c}\text { Chemical resistance of } \\
\text { VEOCN+ } \\
\text { MMA [in terms of } \% \text { wt. loss] }\end{array}$ & $\begin{array}{l}\text { Chemical resistance of VEOCN } \\
\text { +STY [in terms of \% wt. loss] }\end{array}$ \\
\hline \multirow{3}{*}{$\mathrm{HCl}$} & 30 & 0.02 & 0.50 \\
\hline & 60 & 0.04 & 0.60 \\
\hline & 90 & 0.04 & 0.69 \\
\hline \multirow{3}{*}{$\mathrm{NaOH}$} & 30 & 0.18 & 0.60 \\
\hline & 60 & 0.30 & 0.74 \\
\hline & 90 & 0.65 & 0.86 \\
\hline \multirow{3}{*}{$\mathrm{NaCl}$} & 30 & 0.007 & 0.03 \\
\hline & 60 & 0.01 & 0.05 \\
\hline & 90 & 0.25 & 0.33 \\
\hline
\end{tabular}


and salt resistance as compared to that of VEOCN containing styrene which can be attributed to higher degree of curing or crosslinking in the VEOCN resin sample network containing MMA.

As cross linking is the main structural aspect to prevent polymeric chains from dissolving in a solvent, although the consequence of polarity and hydrogen bonding cannot be ignored. Higher the degree of crosslinking, lesser will be free volume and segmental mobility in the polymeric chain array which will prevent the permeation of the solvent molecules to crosslinked structure of VEOCN containing MMA.

\section{Morphological studies}

The cured vinyl ester resin samples taken for the chemical resistance study by immersing in different solutions i.e. $1 \mathrm{M} \mathrm{HCl}, 1 \mathrm{M} \mathrm{NaOH}$ and $1 \mathrm{M} \mathrm{NaCl}$ for 90 days at room temperature are also examined for detecting any morphological or physical change due to above chemical exposure with scanning electron microscopy (SEM). It is evident from the Figure 9 that maximum surface deterioration or cracks has been observed on the surface of cured vinyl ester resin samples containing styrene as reactive monomer after chemical exposure to $1 \mathrm{M} \mathrm{HCl}$, $1 \mathrm{M} \mathrm{NaOH}$ and $1 \mathrm{M} \mathrm{NaCl}$ respectively, whereas only roughness on surface of vinyl ester resin samples containing MMA as reactive monomer has been observed after chemical exposure which shows better chemical resistance of vinyl ester resin samples containing MMA than styrene and is in good agreement with \% weight loss of the cured vinyl ester resin samples during the study of chemical resistance behaviour.

\section{CONCLUSION}

This study reports the findings of an experimental investigation on thermal, mechanical and chemical properties of vinyl ester resin synthesized using styrene and methyl methacrylate as reactive monomers. The synthesis of OCN, EOCN and VEOCN was verified using FT-IR,
${ }^{1} \mathrm{H}-\mathrm{NMR}$ and ${ }^{13} \mathrm{C}$-NMR. Using ${ }^{13} \mathrm{C}$-NMR, it was concluded that the OCN resin was a random novolac since it showed o-o, o-p and $p-p$ linkage. The curing behaviour of VEOCN sample containing methyl methacrylate and styrene as reactive diluents, showed methyl methacrylate to be more reactive as compared to styrene. The result obtained in thermogravimetric studies, showed isothermally cured sample of the VEOCN resin containing styrene to be the more thermally stable as compared to that containing methyl methacrylate as reactive monomer, owing to the presence of aromatic ring. VEOCN sample containing MMA as reactive diluent, showed superior mechanical performance (compression and flexural strength) and better chemical resistance in terms of $\%$ weight loss when exposed to different solutions of $\mathrm{HCl}$, $\mathrm{NaOH}$ and $\mathrm{NaCl}$. The morphological studies of these chemically exposed samples also validate these results, which again show that the sample containing MMA gave better product because of the higher reactivity of MMA which leads to enhanced crosslinked structure.

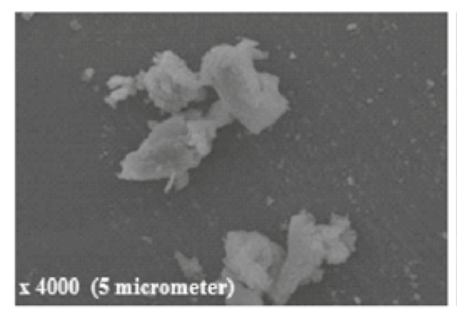

(A)

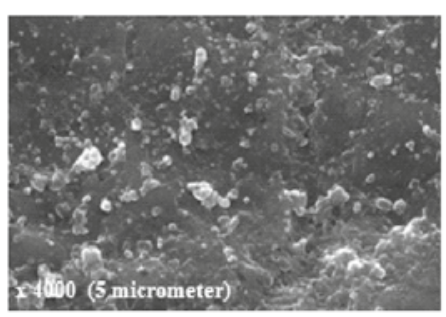

(B)

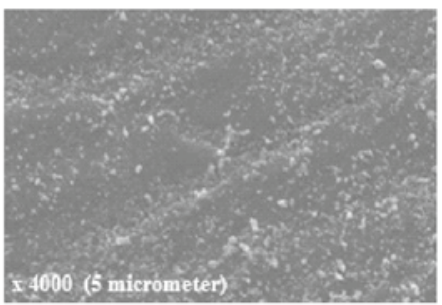

(C)

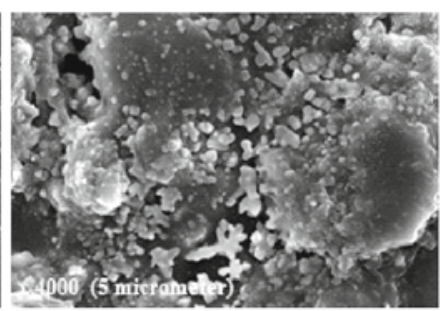

(D)

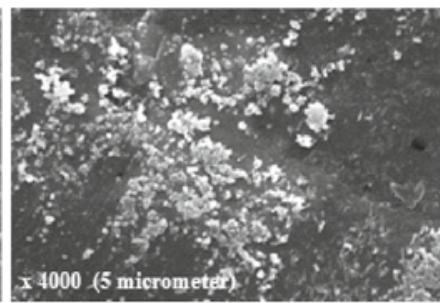

(E)

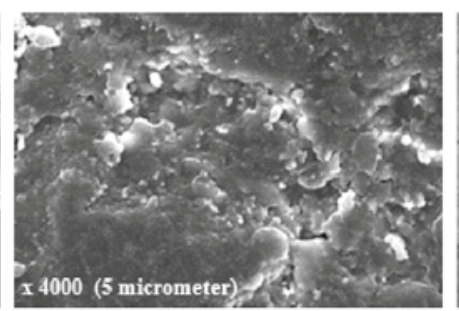

(F)

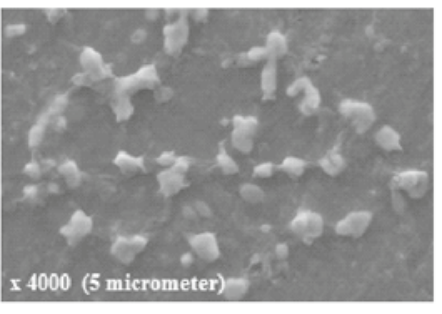

(G)

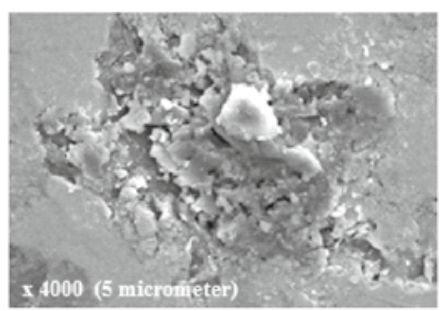

(H)

Figure 9. SEM images of cured vinyl ester resin samples containing MMA and Styrene as reactive diluents. (A) and (B) MMA and Styrene (unexposed), (C) and (D) MMA and Styrene (exposed to $1 \mathrm{M} \mathrm{HCl),} \mathrm{(E)} \mathrm{and} \mathrm{(F)} \mathrm{MMA} \mathrm{and} \mathrm{Styrene} \mathrm{(exposed} \mathrm{to} 1$ $\mathrm{M} \mathrm{NaOH})$ and $(\mathrm{G})$ and $(\mathrm{H}) \mathrm{MMA}$ and Styrene (exposed to $1 \mathrm{M} \mathrm{NaCl}$ ) 


\section{LITERATURE CITED}

1. Suresha, B., Kumar, K.S., Seetharamu, S. \& Kumaran, P.S. (2010). Friction and dry sliding wear behavior of carbon and glass fabric reinforced vinyl ester composites. Tribol. Int. 43, 602-609. DOI: 10.1016/j.triboint.2009.09.009.

2. Kumar, S., Satapathy, B.K. \& Patnaik, A. (2012). Thermomechanical correlations to erosion performance of short glass/ carbon fiber reinforced vinyl ester resin hybrid composites. Comput. Mater. Sci. 60, 250-260. DOI: 10.1016/j.commatsci.2012.03.021.

3. Shahedefar, V. \& Rezadoust, A.M. (2013). Thermal and mechanical behavior of cotton/vinylester composites: Effects of some flame retardants and fibre treatment. J. Reinf. Plast. Compos. 32, 681. DOI: 10.1177/0731684413475911.

4. Stankiewicz, A., Szczygiel, I. \& Szczygiel, B. (2013). Selfhealing coating in anti-corrosion applications. J. Mater. Sci. 48, 8041-8051. DOI: 10.1007/s10853-013-7616-y.

5. Yabuki. A. \& Okumura, K. (2012). Self healing coatings using superabsorbent polymers for corrosion inhibition in carbon steel. Corros. Sci. 59, 258-262. DOI: 10.1016/j. corsci.2012.03.007.

6. Ehsani, M., Khonakdar, H.A. \& Ghadami, A. (2013). Assessment of morphological, thermal and viscoelastic properties of epoxy vinyl ester coating of glass flake and mixing method. Prog. Org. Coat. 76, 238-243. DOI: 10.1016/j.porgcoat.2012.09.010. 7. Ambrogi, V., Carfagna, C., Giamberini, M., Amendola, E. \& Douglas, E.P. (2002). Liquid crystalline vinyl ester resins for structural adhesives. J. Adhes. Sci. Technol. 16, 15-32. DOI: $10.1163 / 15685610252771130$.

8. Launikitis, M.B. (1982). Vinyl Ester Resins, In Handbook of Composites, Luben, G. Ed; Van Nostrand, Reinhold Co.: New York, 38-49.

9. Young, R.E. (1976). In Unsaturated Polyester Technology, Bruins, P.F. Ed.; Gordon and Breach: New York, 315-342.

10. Jaswal, S. \& Gaur, B. (2014). New trends in vinyl ester resins. Rev. Chem. Engg. 30(6), DOI: 10.1515/revce-2014-0012 11. Gaur, B. \& Rai, J.S.P. (1993). Rheological and thermal behavior of vinyl ester resin. Eur. Polym. J. 29, 1149-1153. DOI: 10.1016/0014-3057(93)90324-9.

12. Varma, I.K., Rao, B.S., Choudhry, M.S., Choudhry, V. \& Varma, D.S. (1985). Effect of styrene on properties of vinyl ester resins, I. Angew. Makromol. Chem. 130, 191-199. DOI: 10.1002/apmc.1985.051300116.

13. Choudhary, M.S. \& Varma, I.K. (1993). Vinyl ester resins, 3. Effect of ethyl methacrylate on thermal and mechanical properties. Angew. Makromol. Chem. 209, 33-39. DOI: 10.1002/ apmc.1993.052090104.

14. Gaur, B. \& Rai, J.S.P. (1992). Curing and decomposition behavior of vinyl ester resins. Polym. 33, 4210. DOI: 10.1016/0032-3861(92)90631-6.

15. Malik, M., Choudhary, V. \& Varma, I.K. (2001). Effect of oxirane groups on curing behavior and thermal stability of vinyl ester resins. J. Appl. Polym. Sci. 82, 416-423. DOI: 10.1002/app.1866.

16. Bhatnagar, R. \& Varma, I.K. (1989). Effect of $\alpha$-methylstyrene of the curing behavior of vinyl ester resins. J. Therm. Anal. 35, 1241-1249. DOI: 10.1007/BF01913044.

17. Lem, K.W. \& Han, C.D. (1984). Thermokinetics of Unsaturated Polyester and Vinyl Ester Resins. Polym. Eng. Sci. 24, 175. DOI: 10.1002/pen.760240304.

18. Jaswal, S. \& Gaur, B. (2013). Curing and decomposition behavior of cresol novolac based vinyl ester resins. Chem. Engine. Trans. 32, 1591-1596. DOI: 10.3303/CET1332266.

19. Knoll, D.W., Nelson, D.H. \& Keheres, P.W. (1958). Pap., 134th Am. Chem. Soc. Meet, Chicago, Division of Paint, Plastics and Printing Ink Chemistry, Paper No: 5, p. 20.

20. Gibson, S.L., Glass, T.E., Shultz, A.R. \& Riffle, J.S. (2002). Controlled molecular weight cresol-formaldehyde oligomers. Polym. 43, 2017-2019. DOI: 10.1016/S0032-3861(01)00754-6.
21. Knop, A. \& Pilato, L.A. (1985). Phenolic Resins, SpringerVerlag Berlin Heidelberg, New York Tokyo.

22. Sultania, M., Rai, J.S.P., Srivastava, D. (2010). Studies on the synthesis and curing of epoxidised novolac vinyl ester resin from renewable resource material. Eur. Polym. J. 46, 2019-2032. DOI: 10.1016/j.eurpolymj.2010.07.014.

23. Smith, C.A., (1987). Characterization of Polymers Used in Printed Circuit Board Manufacture. Polym. Test. 7, 79-84. DOI: 10.1016/0142-9418(87)90002-X.

24. Hsu, C.P. \& Lee, L.J. (1993). Free-radical crosslinking copolymerization of styrene/unsaturated polyester resins: 1 . Phase separation and microgel formation. Polym. 34, 4496-4504. DOI: 10.1016/0032-3861(93)90156-5.

25. Hsu, C.P. \& Lee, L.J. (1993). Free-radical crosslinking copolymerization of styrene/unsaturated polyester resins: 3 . Kinetic-gelation mechanism. Polym. 34, 4516-4523. DOI: 10.1016/0032-3861(93)90158-7.

26. Yang, Y.S.C. \& Suspense, L. (1991). Curing of unsaturated polyester resins: Viscosity studies and simulations in pre-gel state. Polym. Engg. Sci. 31, 321-332. DOI: 10.1002/ pen.760310505.

27. Chen, J.S. \& Yu, T.L. (1998). Microgelation of unsaturated polyester resins by static and dynamic light scattering. J. Appl. Polym. Sci. 69, 871-878. DOI: 10.1002/(SICI)10974628(19980801)69:5<871::AID-APP5>3.0.CO;2-J.

28. Chiu, Y.Y. \& Lee, L.J. (1995). Microgel formation in the free radical crosslinking polymerization of ethylene glycol dimethacrylate (EGDMA). I. Experimental. J. Polym. Sci., Part A: Polym. Chem. 33, 257-267. DOI: 10.1002/pola.1005.080330208. 29. Yang, Y.S. \& Lee, L.J. (1988). Microstructure formation in the cure of unsaturated polyester resins. Polym. 29, 1793-1800. DOI: 10.1016/0032-3861(88)90393-X.

30. Han, C.D. \& Lem, K.W. (1984). Chemorheology of thermosetting resins. IV. The chemorheology and curing kinetics of vinyl ester resin. J. Appl. Polym. Sci. 29, 1879-1902. DOI: 10.1002/app.1984.070290538.

31. Dusek, K. \& Spevacek, J. (1980). Cyclization in vinyl- divinyl copolymerization. Polym. 21, 750-756. DOI: 10.1016/00323861(80)90290-6.

32. Ziaee, S. \& Palmese, G.R. (1999). Effect of temperature on cure kinetics and mechanical properties of vinyl-ester resins. J. Polym. Sci., Part B: Polym. Phys. 37, 725-744. DOI: 10.1002/ (SICI)1099-0488(19990401)37:7<725::AID-POLB23>3.0.CO;2-E. 33. Dua, S., Mccullough, R.L. \& Palmese, G.R. (1999). Copolymerization kinetics of styrene/vinyl ester systems: low temperature reactions. Polym. Compos. 20, 379-391. DOI: 10.1002/ pc. 10364 .

34. Ganem, N., Mortaigne, B., Bellenger, V. \& Verdu, J. (1993). Influence of styrene ratio on copolymerization kinetics of dimethacrylate of diglycidylether of bisphenol A vinyl ester resin crosslinked with styrene. J. Macromol. Sci., Pure Appl. Chem. 30, 829-848. DOI: 10.1080/10601329308009592. 35. Ganem, M., Lafontaine, E., Mortaigne, B., Bellenger, V. \& Verdu, J. (1994). Structure of vinyl ester networks: a rubber elasticity study. J. Macromol. Sci. Phys. 33, 155-172. DOI: 10.1080/00222349408248085. 